\title{
Role of RDW and MPV in Diagnosis of Colorectal Polyps and Carcinoma: A Case-Control Study
}

\section{Kolorektal Polip ve Karsinom Tanısında RDW ve MPV'nin Rolü: Vaka-Kontrol Çalışması}

\author{
Mustafa Cengiz ${ }^{1}$, Abdurrahman Şahin ${ }^{2}$, Kamil Özdil $^{3}$, Hacı Mehmet Sökmen ${ }^{3}$ \\ ${ }^{1}$ Dr. A. Y. Ankara Onkoloji Eğitim Ve Araştırma Hastanesi, Gastroenteroloji Bölümü, Ankara, \\ Türkiye. \\ ${ }^{2}$ Fırat Üniversitesi Tıp Fakültesi, Gastroenteroloji Bölümü, Elâzı̆̆, Türkiye. \\ ${ }^{3}$ Ümraniye Eğitim Ve Araştırma Hastanesi, Gastroenteroloji Bölümü, İstanbul, Türkiye.
}

Dergiye Ulaşma Tarihi:28/04/2015 Dergiye Kabul Tarihi:28/05/2015 Doi: 10.5505/aot.2015.96268

\section{ÖZET}

Giriş ve Amaç: Ortalama trombosit hacmi (MPV) kırmızı kan hücresi dağılım genişliği (RDW) testleri rutin tam kan sayımında bulunan basit testlerdir. İnflamasyon, MPV ve RDW değerlerinde değișiklikler yapabilir. Bu çalışmada KRK, adenom ve sağlıklı kontrollerin MPV ve RDW değerlerini karşılaştırmayı amaçladık.

Yöntem ve Gereçler: KRK veya irritabl barsak hastalığı şikâyetleri nedeniyle kolonoskopik tarama yapılan vakaların MPV ve RDW değerleri geriye dönük olarak değerlendirilmiştir. Kolonoskopi ve histopatolojik bulgularına göre göre hastalar KRK, adenom ve normal kontrol grubu olmak üzere 3 ayrı gruba ayrıldı. Sonrasında adenom grubu displazi ve villöz komponent varlığına göre yüksek olasılıklı prekanseröz ve düşük olasılıklı prekanseröz olarak 2 alt gruba ayrıldı.

Bulgular: Çalışmaya ardışık toplam 602 hasta alındı. Bunlardan KRK grubunda $(\mathrm{n}=130)$ 'si, adenom grubunda $(n=241)$ 'si ve normal kolonoskopik bulguları olan $(n=233)$ 'si hasta kontrol grubundaydı. KRK grubunda diğer gruplara nazaran hemoglobin, $\mathrm{MCV}$ değerleri daha düşükken trombosit sayıları daha yüksek bulundu $(\mathrm{P}<0.001)$. MPV ortanca değerleri KRK, adenom ve kontrol grupları arasında karşılaştırıldığında sırasıyla (7,51-7,91-7,90 ve $\mathrm{P}<0,001)$. Ayrıca RDW median değerleri gruplara arasında $(15,7-14,6-14,4$ ve $\mathrm{P}<0,001)$ istatistiksel olarak anlamlı bulundu. Adenom alt grupları karşılaştırıldığında düşük-yüksek olasılıklı gruplar arasında sadece RDW açısından istatistiksel anlamlı fark tespit edildi $(14,4-14,8$, ve $\mathrm{P}=0.02)$. MPV değerleri açısından gruplar arasında fark bulunamadi $(7,89-8,04$ ve $\mathrm{P}>0.05)$.

Tartışma ve Sonuç: Kolonoskopik taramaya alınacak vakalarda RDW ve MPV değerleri dikkate alınmalıdır.

Anahtar Kelimeler: Adenom, Karsinom, MPV, RDW

\section{ABSTRACT}

Introduction: Mean platelet volume (MPV) and red cell distribution width (RDW) are simple tests in routine complete blood count. We aimed to evaluate RDW and MPV values of patients with colorectal carcinoma (CRC), adenoma and healthy controls.

Methods: The MPV and RDW values of participants who underwent colonoscopic examination for CRC screening or irritable bowel syndrome related symptoms were evaluated retrospectively. Patients were divided into three groups as CRC group, adenoma group and control group according to colonoscopic and histopathological findings..Patients with adenomas were separated into two subgroups according to dysplasia and villous component as high probable precancerous (HPP) and low probable precancerous (LPP) groups.

Results: A total of consecutive 602 participants were enrolled into the study. There were $n=130$ patients in CRC, $\mathrm{n}=241$ patients adenoma group and $\mathrm{n}=233$ in control group. The CRC group had lower hemoglobin levels, MCV values and higher platelet count compared to adenoma group and control group. The median MPV values of CRC group (7.51) were lower than adenoma group (7.91) and control group (7.90) $(\mathrm{P}<0.001$, for both). The median RDW value of CRC group (15.7) was significantly higher than adenoma group (14.6) and controls (14.4) $(\mathrm{P}=0.01$, for both). Adenoma subgroups comparison reveals that the only different parameter was RDW between LPP and HPP (14.4 vs. 14.8, P=0.02). The MPV values are similar in both groups (7.89 vs. 8.04, P>0.05). Discussion and Conclusion: The RDW and MPV values should be taken into consideration in patients who underwent colonoscopic screening.

Key words: Adenoma, carcinoma, MPV, RDW 


\section{Giriş}

Kolorektal kanser (KRK) dünyada kanser ilişkili morbidite ve mortalitenin en sik nedenlerinden biridir (1). Kanserlerin \%95'inden fazlası adenomatöz polipten orijin alır. KRK'lerin büyük bir çoğunluğu normal görünümlü mukozadan adenoma, displazi ve nihai olarak karsinoma geçiş gösteren siralı yolakla meydana gelir. Genelde 50 yaşından sonra adenomatöz polipler sıklıkla görülmekle beraber poliplerin büyük bir çoğunluğu adenokarsinoma ilerlemez (2). Yüksek evre displazi ve önemli villöz komponent gibi bazı histolojik özelliklerin nihai kanser oluşmasını tahmin etmede değerleri vardır. KRK tanısinın erken konması kanser ilişkili mortaliteyi azaltmakta ve sağkalımı arttırmaktadır. Ayrıca KRK taraması bazılarının prekanseröz özellikleri olabilecek poliplerin tespit edilmesinde ve çıkarılmasında önem arz etmektedir. $\mathrm{Bu}$ bulguların doğrultusunda kolonoskopik takip önerilmektedir. KRK taraması için gaitada gizli kan, kolonoskopik veya radyolojik prosedürler uygulanmaktadır. Ancak KRK taraması için yaygın bir şekilde kabul gören herhangi bir kan testi bulunmamaktadır.

Kırmız1 kan hücreleri (RBC), beyaz kan hücreleri ve trombositleri içeren dolaşımdaki kan hücrelerinin sayılıp şekillendirilmesi için elektronik analiz cihazları kullanılmaktadır. Toplam hücre sayımı yapılmasının yanı sira bu cihazlar ayrıca ortalama hücre hacmini ve hücre boyutunun dağılımını tahmin etmede kullanılmaktadırlar. Kırmızı hücre dağılım genişliği (RDW) eritrosit popülasyonunun değişkenliğinin ölçüsüdür (3). Artmış RDW retikülositlerin dolaşıma olgunlaşmadan salınmasına neden olan bir sürü hastalıkta görülebilir. Aneminin ayrıcı tanısının yanı sıra yükselmiş RDW değerleri kalp yetmezliğgi, kardiyovasküler olaylar, çölyak hastalığı ve inflamatuar barsak hastalığı aktivitesi ile ilişkili bulunmuştur (4). Ayrıca RDW'deki artışların artmış inflamatuar markırlarla ilişkili olduğu bulunmuştur $(5,6)$.

Trombositler; koagulasyonda, inflamasyonda, trombozda ve aterosklerozda önemli rol oynayan çok sayıda cisimleri üretir ve salgılarlar. Ortalama trombosit hacmi (MPV) inflamasyonu gösteren ve en geniş olarak çalışılan moleküllerden biridir. Trombosit sayıs1 ve MPV birbiriyle ters ilişkilidir böylelikle toplam trombosit kütlesi yaklaşık olarak sabit kalmaktadır (7). Yüksek MPV belirlenmiş değişik önemli risk faktörleri ile ilişkili bulunmuştur ve kardiyovasküler, serebrovasküler hastalıklar ve arteryal ve venöz tromboza neden olan düşük evre inflamasyonla ilişkilidir. Yüksek evre inflamasyonla ilişkili olan romatoid artrit veya Ailevi Akdeniz Ateş (FMF) ataklarında düşük MPV değerleri tespit edilmiş̧ir (8). Literatürde kanser hastalarının RDW değerlerini araştıran az sayıda çalışma bulunmaktadır $(9,10)$. Ayrica kanser hastalarının MPV değerlerini araştıran çalışmaların sayısı daha da azdır (11). Öyle ki bu çalışmalarda hem Kürk'le hasta sayısı az hem de sağlıklı kontrollerle karşılaştırma yapılmamıştır. Ayrıca literatürde kolon adenomlarının RDW ve MPV değerleri hakkında veri bildiğimiz kadarıyla bulunmamaktadır.

$\mathrm{Bu}$ çalışmada amacımız; KRK tanis1 alan hastalar veya kolon polipi olan hastaların RDW ve MPV değerlerinin normal sağlıklı kontrollerin değerleriyle karşılaştırılmasıdır. Ayrıca alt grup analizde düşük ve yüksek derece displazili adenomları olan hastaların değerlerini karşılaştırmayı amaçladık.

\section{Gereç ve Yöntem}

\section{Hastalar:}

$\mathrm{Bu}$ retrospektif çalışmaya KRK taraması veya irritabl barsak hastalığı şikayetleri nedeniyle total kolonoskopi yapılan hastalar alınd. Vakalar kolonoskopik ve histopatolojik bulgularına göre KRK grubu, adenom grubu ve normal kontrol olmak üzere 3 ayrı gruba ayrıldı. Hastaların demografik özellikleri, kolonoskopi yapılma nedenleri, yaş, cinsiyet, eski tıbbi hikaye ve kolonoskopi işlemi esnasında laboratuvar testleri binası önlemek için hastaların bulgularından haberdar olmayan klinisyen tarafindan veri tabanına kaydedildi. Kolonoskopi 
işleminden önce hastaların onayı alındı. Vakaların demografik ve klinik bilgileri analiz edildi. Kanseri olan hastalar anemi durumuna bakılmaksızın çalışmaya alındı. Öncesinde KRK nedeniyle opere olan ve kolonoskopik takip için işlem yaptıran hastalar çalışmadan dışlandı. Tam kan sayım (CBC) değerleri tanı anında ve herhangi bir kan ürünü replasmanı yapılmadan elde edilen kanlardan çalışıldı.

Kolon polipi olan hastalar histopatolojik olarak displazi derecesine ve villöz komponent varlığına göre 2 ayrı alt gruba ayrıld1; yüksek olasılıklı prekanseröz (yüksek dereceli displazi veya villöz adenom) ve düşük olasılıklı prekanseröz (tübüler/tübülövillöz adenom ve düşük derece displazi). Kolonoskopi esnasinda birden fazla polip tespit edildiğinde derecesi en yüksek olan displazi ile villöz komponenti olan polip çalışmaya alındı. Kolonoskopide polip tespit edilen veya kolonoskopik bulguları normal olan vakaların son 3 ayda var olan $\mathrm{CBC}$ değerleri çalışmaya dahil edilmiştir. Kronik diyare veya demir eksikliği anemisi etiyolojisini aydınlatmak için kolonoskopi yapılıp işlemde normal veya polip tespit edilen hastalar yanlış sonuçları engellemek için dışlanmıştır.

Bütün gruplar için, RDW veya MPV değerlerini etkileyecek diyabet, tiroit disfonksiyonu, inme, tromboembolik olaylar, kalp yetmezliği, kardiyovasküler olaylar ve inflamatuar bozuklukları gibi kronik rahatsızlığ1 olan hastalar çalışmadan dışlanmıștır. Ayrıca hem RDW hem de MPV değerlerine ulaşılamayan hastalar çalışmadan dışlanmıştır.

\section{Laboratuvar testleri:}

Hemoglobin (HB), mean corpuscular volume (MCV), RDW, trombosit say1s1, beyaz küre (WBC) ve MPV değerleri Advia 2120 (Siemens Healthcare Diagnostics Inc., Tarrytown, New York, USA) cihazı kullanılarak tespit edilmiştir. Ayrica RDW hesaplaması (standart sapma (SD)/MCV X 100\%) denklemi kullanılarak yapılmıştır.

\section{İstatistiksel analizler:}

İstatistiksel analizler SPSS 21. Versiyonu kullanılarak yapıldı. Değişkenler normal dağılıp dağılmadığını araştırmak için görsel (histogram, olasılık plotları) ve analitik metotlar (KolomogorovSmirnov/Shapiro-Wilk's testleri) kullanıldı. Normal dağılım gösteren değişkenler için ortalama ve standart sapma kullanılırken normal dağılmayan değişkenler için ortanca ve aralık değerleri verildi. Normal dağılım gösteren değişkenler 3 grup arasında karşılaştırılınca varyans analiz ile değerlendirme yapıld 1 ve bonferroni düzeltmesi Student $\mathrm{T}$ testi ile yapild. Normal dağılmayan değişkenler için Kruskal Wallis testleri ve Bonferroni düzeltmesi Mann-Whitney $U$ testi kullanılarak yapıldı. Ayrıca düşük derece ve yüksek derece displazi grupları arasında parametreler Man Whitney U testi kullanılarak değerlendirildi. P değeri için 0,05 'ten küçük olan değerler istatistiksel olarak anlamlı kabul edildi.

\section{Sonuçlar}

$\mathrm{Bu}$ çalışmaya toplamda 602 ardışık vaka alınd. Vakalar KRK grubu, adenom grubu ve normal kontrol olmak üzere 3 ayrı gruba ayrildi. Karsinom grubunda 130 hasta varken bunların \%57,7'si erkekti. Toplamda 241 adenom hastasının \%64,5'i erkek hastalardan oluşuyordu. Ayrıca kolonoskopisi normal olan 233 sağlıklı vaka çalışmada yer aldı. KRK grubunda bulunan vakaların yaşları diğer her iki gruptan daha büyüktü ve fark istatistiksel olarak anlamliydı $(\mathrm{P}<0.001)$. Cinsiyet açısından gruplar arasında istatistiksel olarak anlamlı farklılık yoktu.

Karsinom grubunda diğer her iki gruba nazaran daha düşük $\mathrm{HB}$ ve $\mathrm{MCV}$ değerleri bulunurken trombosit değerleri daha yüksek bulundu ve farklılık istatistiksel olarak anlamlıydı (Bütün değişkenler için $\mathrm{P}<0,001)$. Trombosit sayıs1 adenom grubunda sağliklı gruba göre daha düşüktü $(\mathrm{P}=0.03)$ ayrıca $\mathrm{MCV}$ değerleri daha yüksekti $(\mathrm{P}=0,03)$. MPV değerleri karşılaştırıldığında karsinom, adenom ve sağlıklı grupların değerleri sirasiyla 7,51 (5,6-11,1)-7,91 (5,89-13,70)$7,90 \quad(5,89-18,60)$ olarak tespit edildi. Karsinom ve adenom grupları ve karsinom 
ile kontrol grupları arasinda MPV açısından anlamlı istatistiksel fark bulunurken $(\mathrm{P}<0,001)$. Polip grubu ile kontrol grubu arasinda istatistiksel anlamlı fark bulunamadı $(\mathrm{P}>0,05)$. Ayrıca ortanca RDW değerleri açısından gruplar karşılaştırıldığında KRK grubunda adenom grubuna göre daha yüksek değerler tespit edildi. (15,7 ile14,6 ve $\mathrm{P}<0,001)$. Ayrica KRK grubu ile kontroller arasında da RDW açısından istatistiksel anlaml fark bulundu (15,7 ile $14,4$ ve $\mathrm{P}<0,001)$. Ancak adenom grubu ile kontrol grubu arasında anlamlı fark bulunamadı $(14,6$ ile 14,4 ve $\mathrm{P}>0.05)$. Çalışmaya alınan vakaların klinik özellikleri ve laboratuvar değerlerinin karş1laştırılması Tablo 1'de özetlenmiştir. Ayrica MPV ve RDW değerlerinin gruplar arasında karşılaştırılması sırasıyla Şekil 1 ve Şekil 2'de gösterilmiştir.

Tablo 1: Vakaların klinik özellikleri ve laboratuvar değerlerinin karşılaştırılması

\begin{tabular}{|l|l|l|l|l|}
\hline & $\begin{array}{l}\text { Kontrol } \\
\text { grubu }\end{array}$ & Adenom grubu & Karsinom grubu & P değeri \\
\hline Yaş (y1l) & $53,3 \pm 13,1$ & $57 \pm 11,8$ & $62,8 \pm 12,8$ & $<0.001$ \\
\hline Cinsiyet Erkek (\%) & $136(\% 58,6)$ & $156(\% 64,5)$ & $75(\% 57,7)$ & 0.26 \\
\hline Hemoglobin ${ }^{\mathrm{a}}$ (g/dL) & $\begin{array}{l}13,8(12,1- \\
17,3)\end{array}$ & $14(11,9-17,7)$ & $11,8(5,7-19,6)$ & $<0.001$ \\
\hline $\begin{array}{l}\text { Trombosit }^{\text {a }} \\
\left(/ \mathrm{mm}^{3} \times 10^{3}\right)\end{array}$ & $\begin{array}{l}259(125- \\
509)\end{array}$ & $252(122-526)$ & $335(98-822)$ & $<0.001$ \\
\hline MPV $^{\text {a }}(\mathrm{fL})$ & $\begin{array}{l}7,9(5,89- \\
18,6)\end{array}$ & $7,91(5,92-13,7)$ & $7,51(5,6-11,1)$ & $<0.001$ \\
\hline RDW & $\begin{array}{l}\text { a }(\%) \\
14,4(11,2-\end{array}$ & $14,6(11,4-23,5)$ & $15,7(7,3-27,3)$ & $<0.001$ \\
\hline MCV $^{\text {a }(f L)}$ & $\begin{array}{l}86,5(62,9- \\
97,5)\end{array}$ & $87,3(66,9-99,3)$ & $83,3(63,4-98)$ & $<0.001$ \\
\hline
\end{tabular}

MCV: ortalama corpuscular hacim RDW: Kırmızı kan hücresi dağılım genişliği; MPV: Ortalama trombosit hacmi. ( $\left.{ }^{a}\right)$ Data median olarak temsil edilmiştir (range).

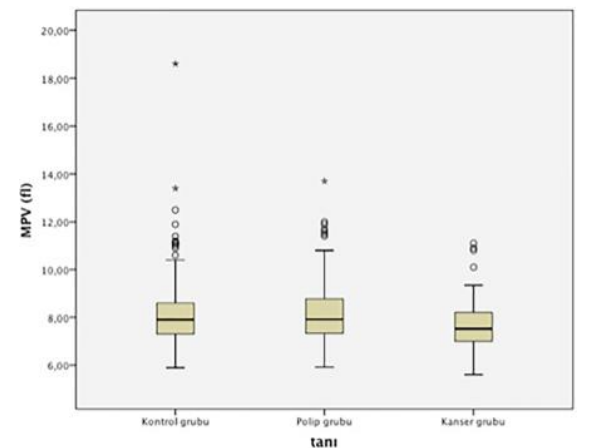

Şekil 1: Grupların MPV değerlerinin karşılaş.

Polip grubu düşük olasılıklı prekanseröz ve yüksek olasılıklı prekanseröz olmak üzere 2 gruba ayrılmıștı. Düşük olasılık grubunda 148 hasta bulunurken yüksek olasıllk grubunda 93 hasta bulunuyordu. Yaş açısından yüksek olasılık grubu daha yaşlı hastalardan oluşmaktaydı. Bu alt grupların demografik ve karakteristik özellikleri ve CBC sonuçlarının karşılaştırılması Tablo

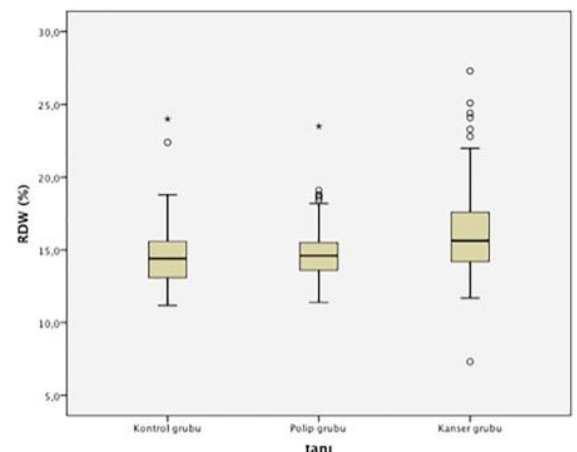

Şekil 2: Grupların RDW değerlerinin karşılaş.

2' gösterilmiştir. RDW değerleri yüksek olasılık grubunda daha yüksek olmak üzere her iki grup arasında karşılaştırıldığında farklılık istatistiksel olarak anlaml bulundu $(14,4$ ile 14,8 ve $\mathrm{P}=0.02)$. $\mathrm{Bu}$ karşılaştırma Şekilde 3'te gösterilmiştir. Ancak MPV değerleri gruplar arasında istatistiksel olarak anlamlı farklı değildi $(7,89$ ile 8,04 ve $\mathrm{P}>0.05)$. 
Tablo 2: Polip alt grupların demografik ve laboratuvar özelliklerinin karşılaş̧ırılması.

\begin{tabular}{|l|l|l|l|}
\hline & Düşük derece grup & Yüksek derece grup & P değeri \\
\hline Yaş (y1l) & $55,2 \pm 12,4$ & $59,7 \pm 10,3$ & $<0.001$ \\
\hline Cinsiyet Erkek (\%) & $91(\& 61,5)$ & $64(\% 68,8)$ & 0,25 \\
\hline Hemoglobin $^{\mathrm{a}}(\mathrm{g} / \mathrm{dL})$ & $14,2(11,9-17,7)$ & $13,9(11,9-17,5)$ & 0,47 \\
\hline${\text { Trombosit }\left(/ \mathrm{mm}^{3} \times 10^{3}\right)}^{3}$ & $251(122-518)$ & $252(139-526)$ & 0,81 \\
\hline MPV $^{\mathrm{a}}(\mathrm{fL})$ & $7,89(6,5-11,9)$ & $8,04(5,92-13,7)$ & 0,48 \\
\hline RDW $^{\mathrm{a}}(\%)$ & $14,4(11,4-23,5)$ & $14,8(12,7-19,1)$ & 0,02 \\
\hline $\mathrm{MCV}^{\mathrm{a}}(\mathrm{fL})$ & $87,1(66,9-99,3)$ & $87,3(69,2-97,2)$ & 0,81 \\
\hline
\end{tabular}

MCV: ortalama corpuscular hacim RDW: Kırmızı kan hücresi dağııım genişliği; MPV: Ortalama trombosit hacmi. $\left({ }^{\mathrm{a}}\right)$ Data median olarak temsil edilmiştir (range).

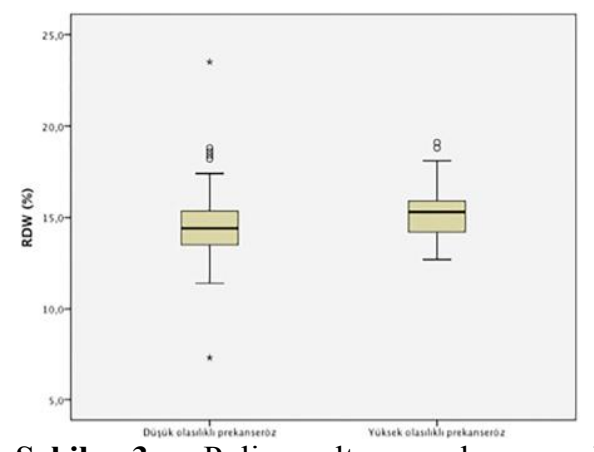

Şekil 3: Polip alt gruplarının RDW değerlerinin karşılaştırılması

\section{Tartışma}

$\mathrm{Bu}$ çalışmada KRK grubu, adenom grubu ve kontrol gruplarının CBC parametrelerini karşılaştırdık ve sonuçta KRK hasta grubunda RDW değerlerinde artış izlenirken MPV değerlerinde düşüş olduğu tespit edildi. Kolonik poliplerin ise CBC parametreleri üzerine ciddi bir etkileri olmadığı görüldü. Polip özelliğine göre tek anlamlı farklılı RDW değerlerinde tespit edildi.

Aşikar veya gizli gastrointestinal sistem kanamaları KRK en önemli bulgularından biridir. Gastrointestinal kanama ve demir eksikliği anemisi erkeklerde ve menopoz sonrası kadınlarda kolorektal değerlendirme için 2 önemli endikasyondur. Gastrointestinal sistemden kronik kan kaybı demir eksikliği anemisi yapar öyle ki demir eksikliği anemisine bağlı olarak KRK hastalarında $\mathrm{HB}$ ve MCV değerleri düşük bulunurken RDW ve trombosit değerleri yüksek bulunur. Bizim sonuçlarımız bu gerçekle uyuşmaktadır. Ayrıca Spell ve ark'ının yaptığı bir çalışmada RDW değerlerinin sağ kolon kanserlerinde yüksek derecede sensitif ve spesifik olduğu tespit edilmiş. $\mathrm{Bu}$ çalışmada kontrol grubunda \%12'lik bir RDW yüksekliği tespit edilmişken KRK grubunda bu oran \%69 olarak bulunmuş. Sağ taraf KRK, sol taraf KRK ve kontrol gruplarının ortalama RDW değerleri sırasıyla 16,8- 15- 13,3 olarak bulunmuş. İlginç olarak $\mathrm{CBC}^{\prime}$ 'nin diğer parametreleri (HB, MCV) ile RDW'nin kombinasyonunda tek başına RDW'nin sensitivite ve spesifitesini artıramamıştır. Eritrosit hacmindeki değişkenlik aşikar anemiden önce ortaya çıkmaktadır ve normal CBC ile birlikte artmış RDW erken demir eksikliği anemisinin iyi sensitif ve spesifik bir belirtecidir (9). Ayrıca demir eksikliğini tespit etmekte artmış RDW diğer laboratuvar testlerinden daha duyarlıdır (12).

Yapılan bazı çalışmalarda tıbbi checkup için başvuran hastalarda anemi durumundan bağımsız olarak RDW değerlerinin inflamatuar markırlarla (yüksek sensitif C reaktif protein (CRP) ve eritrosit sedimantasyon hızı (ESR)) ilişkili olduğu bulunmuştur (5, 13). İnflamasyonun eritropoez ve dolaşımdaki eritrosit yarı ömrü üzerindeki etkisi anizositoza neden olup RDW değerlerinde artışa neden olabilmektedir (14). Yapılan bir çalışmada RDW değerlerindeki 1 SD artışın kanser mortalitesinde \%28'lik bir artışla ilişkisi olduğu tespit edilmiştir. İlginç olarak RDW'nin mortalite ile olan ilişkisi inflamasyonun varlığına bağımlı değildi (6). Bizim çalışmamızda kanser bağımlı inflamasyon ve kronik hastalık anemisi anemi durumu ve artmış RDW durumu ile ilişkili olabilir. yapıdaki

Dolaşımdaki küçük ve büyük trombositlerin 
inflamasyonun şiddeti değerlendirilmelidir (8). Artmış MPV düzeyleri genelde vasküler risk faktörleri, immün trombositopenik durumlar, düşük derece inflamatuar durum ve edinsel dev trombosit bozukluklarla ilişkilidir. Düşük MPV değerleri ise sitotoksik tedavi sonras1 kemik iliği aplazisi, hipersplenizm, reaktif trombositozis yüksek dereceli inflamasyon ve Wiskott-Aldrich sendromu ile ilişkilidir (15). Kanser bir sürü proinflamatuar sitokinin salg1landığ $\breve{1}_{1}$ sistemik inflamatuar bir bozukluktur. Birkaç proinflamatuar sitokin kemik iliğindeki hematopoetik hücrelerin maturasyonuna etki ederek hematopoetik hücrelerin dolaşıma salgılanmasına neden olur. Yüksek derece inflamasyonla ilişkili durumlar (aktif inflamatuar barsak hastalığ 1 , Romatoid Artrit, FMF atağında) genel olarak dolaşımdaki küçük trombositlerle ve düşük MPV değerleri ile ilişkili iken aynı durumlar remisyonda iken veya antiinflamatuar ilaç kullanımı dolaşımdaki daha büyük trombositlerle ve daha yüksek MPV değerleri ile ilişkilidir (8). Yüksek derece inflamasyon MPV ile negatif ilişkilidir. Adenomdan karsinom gelişimi malign hücrelerin mukozal tabakay1 geçmesi ve sonuç olarak sistemik yüksek inflamatuar durum oluşması ile sonuçlanır. Öyle ki KRK hastalarında düşük MPV değerleri beklenen bir durumdur.

$\mathrm{Bu}$ çalışmada MPV'nin KRK ve adenom ile olan ilişkisini araştırdık ve kolon poliplerinin MPV üzerine önemli bir etkinliği olmadığı sonucuna vardık ancak düşük MPV değerleri KRK ile ilişkiliydi. Yapılan bir çalışmada Bevacizumab tedavisi alan metastatik KRK hastalarında MPV değerlendirilmiş (11). Bu çalışmada bulunan ortalama MPV değerleri bizim sonuçlardan daha yüksek olarak bulunmuş. Öyle ki bu çalışmadaki hastaların çoğu opere olmuş ve metastatik KRK olarak sınıflandırılmış. Bizim daha düşük MPV değerlerini bulmamızın bir nedeni de hastaların opere olmadan ve tanı konar konmaz değerlerine bakılmas1 nedeniyledir. Öyle ki metastatik KRK hastalarının bir kısmında kitle rezeke edilmediği için değerlendirme aşamasında lezyondan salınan bazı sitokinler megakaryosit ve MPV değerlerini etkilemiştir. Ayrıca biz çalışmamızda opere olmuş ve takip kolonoskopi olan hastaları dıșladığımız için bizim değerler daha düşük olarak bulundu. Böylelikle bizim sonuçlarımızla KRK'nin net olarak MPV üzerine olan etkisi net ve açık olarak tespit edilmiş olmaktadır. Adenom ve kontrol grupları karşılaştırıldığında anlamlı fark bulamadık ayrıca düşükyüksek olasılık prekanseröz adenomlar arasında da istatistiksel anlamlı fark bulunmadı. Bu sonuç gösteriyor ki; polipi olan hastalarda polipin özelliğinden bağımsız olarak mukoza tabakasına sınırlanmış düşük derece inflamasyon MPV değerlerine etki etmemektedir. Öte yandan prekanseröz derecesi ile RDW arasında ilişki tespit edildi. Düşük derece inflamasyon RDW değerlerini etkilerken MPV değerleri etkilenmemektedir. İnflamasyonun mukozanın ötesine geçmesiyle trombositoz ve MPV düşüşü meydana gelmektedir.

Çalışmamızın bazı kısıtlamaları mevcuttu şöyle ki; retrospektif dizayn olmas1, nispeten özellikle adenom grubunda düşük hasta sayısı varlığı olarak sayılabilir. Ayrıca retrospektif dizayndan dolayı polip çapı değerlendirilemedi. Ancak polip çap1 hem yapan kişiye bağlıdır hem de genelde yaklaşık olarak değerlendirildiği için sağlıklı sonuç vermeyecektir. Kişiler arasındaki bu değişkenliğin etkisinden kurtulmak için polip boyutu ile değerlendirme sübjektif olabileceği için çalışmada değerlendirilmemiştir. Ayrıca biz bu çalışmada KRK hastaların tanı anındaki CBC değerlerini değerlendirdik ilerde prospektif olarak tanı anında, operasyon sonrasi ve kemoradyoterapi sonras1 değerlendirme yapılması hastalık trendinde bu markerlerin rolünü daha iyi bildirecektir.

Sonuç olarak, KRK hastalarında MPV değerleri düşük olarak bulunurken displazi ve adenomun villöz komponenti varlığı RDW değerlerini arttırmaktadır. Bu çalışmanın sonuçlarına göre, kolonoskopik tarama yapilacak hastalarda RDW ve MPV değerleri dikkate alınmalıdır. Kanser ve inflamasyonun kemik iliği dolaşımdaki hematopoetik hücreler üzerine etkilerini 
araştırmak için randomize kontrollü ve prospektif çalışmalara ihtiyaç vardır.

\section{Çıkar Çatışması: Yok}

\section{Kaynaklar:}

1. Ferlay J, Shin HR, Bray F, Forman D, Mathers C, Parkin DM. Estimates of worldwide burden of cancer in 2008: GLOBOCAN 2008. Int J Cancer 2010; 127: 2893-2917

2. Levin B, Lieberman DA, McFarland B, Andrews KS, Brooks D, Bond J et al. Screening and surveillance for the early detection of colorectal cancer and adenomatous polyps, 2008: a joint guideline from the American Cancer Society, the US Multi-Society Task Force on Colorectal Cancer, and the American College of Radiology. Gastroenterology 2008; 134: $1570-1595$

3. Dixon LR. 1997. The complete blood count: physiologic basis and clinical usage. J Perinat Neonatal Nurs 1997; 11: 1-18

4. Song CS, Park DI, Yoon MY, Seok HS, Park $\mathrm{JH}$, Kim HJ et al. Association between red cell distribution width and disease activity in patients with inflammatory bowel disease. Dig Dis Sci 2012; 57: 1033-1038

5. Lippi G, Targher G, Montagnana M, Salvagno GL, Zoppini G, Guidi GC. Relation between red blood cell distribution width and inflammatory biomarkers in a large cohort of unselected outpatients. Arch Pathol Lab Med 2009; 133: 628-632

6. Perlstein TS, Weuve J, Pfeffer MA, Beckman JA. Red blood cell distribution width and mortality risk in a community-based prospective cohort. Arch Intern Med 2009; 169: 588-594
7. Bath PM, Butterworth RJ. Platelet size: measurement, physiology and vascular disease. Blood Coagul Fibrinolysis 1996; 7: 157-161

8. Gasparyan AY, Ayvazyan L, Mikhailidis DP, Kitas GD. Mean platelet volume:a link between thrombosis and inflammation? Curr Pharm Des 2011; 17: 47-58

9. Spell DW, Jones DV, Jr., Harper WF, David Bessman J. The value of a complete blood count in predicting cancer of the colon. Cancer Detect Prev2004; 28: 37-42

10. Baicus C, Caraiola S, Rimbas M, Patrascu R, Baicus A. Utility of routine hematological and inflammation parameters for the diagnosis of cancer in involuntary weight loss. J Investig Med 2011; 59: 951-955

11. Mutlu H, Berk V, Karaca H, Erden A, Aslan T, Akca Z. Treatment regimen with bevacizumab decreases mean platelet volume in patients with metastatic colon cancer. Clin Appl Thromb Hemost 2012; 18: 546-548

12. Van Zeben D, Bieger R, van Wermeskerken RK, Castel A, Hermans J. Evaluation of microcytosis using serum ferritin and red blood cell distribution width. Eur J Haematol 1990; 44: 106-109

13. Lappe JM, Horne BD, Shah SH, May HT, Muhlestein JB, Lappe DL et al. Red cell distribution width, C-reactive protein, the complete blood count, and mortality in patients with coronary disease and a normal comparison population. Clin Chim Acta 2011; 412: 20942099

14. Weiss G, Goodnough LT. Anemia of chronic disease. N Engl J Med 2005; 352: 1011-1023

15. Aksoy S, Kilickap S, Hayran M, Harputluoglu H, Koca E, Dede DS ve ark. Platelet size has diagnostic predictive value for bone marrow metastasis in patients with solid tumors. Int $\mathrm{J}$ Lab Hematol 2008; 30: 214-219. 